\title{
Alpha-smooth muscle actin-positive fibroblasts promote biliary cell proliferation and correlate with poor survival in cholangiocarcinoma
}

\author{
CHANISA CHUAYSRI ${ }^{1,4}$, PETI THUWAJIT ${ }^{1,4,6}$, ANUCHA PAUPAIROJ ${ }^{2,4}$, SIRI CHAU-IN $^{3,4}$, \\ TUANGPORN SUTHIPHONGCHAI ${ }^{5}$ and CHANITRA THUWAJIT ${ }^{1,4,7}$
}

\begin{abstract}
Departments of ${ }^{1}$ Biochemistry, ${ }^{2}$ Pathology and ${ }^{3}$ Surgery, Faculty of Medicine, ${ }^{4}$ Liver Fluke and Cholangiocarcinoma Research Center, Khon Kaen University, Khon Kaen 40002; ${ }^{5}$ Department of Biochemistry, Faculty of Science, Mahidol University, Bangkok 10400; ${ }^{6}$ Division of Medical Molecular Biology, Office for Research and Development, ${ }^{7}$ Department of Immunology, Faculty of Medicine Siriraj Hospital, Mahidol University, Bangkok 10700, Thailand
\end{abstract}

Received September 30, 2008; Accepted December 4, 2008

DOI: 10.3892/or_00000309

\begin{abstract}
Cancer-associated fibroblasts have been proposed to play a role in promoting carcinogenesis and tumor progression. To our knowledge, no direct evidence concerning fibroblasts in the genesis of cholangiocarcinoma (CCA) has previously been presented. This study aims to assess the value of activated fibroblasts with high alpha-smooth muscle actin ( $\alpha$-SMA) expression as an indicator for survival in CCA patients. The immunohistochemistry results indicated a high expression of $\alpha$-SMA in CCA fibroblasts which had a statistically significant correlation with larger tumor size $(\mathrm{P}=0.009)$ and shorter survival time $(\mathrm{P}=0.013)$. The effect of $\mathrm{CCA}$-associated fibroblasts (Cfs) on non-tumorigenic biliary epithelial cells (H-69) and CCA cell lines was investigated in vitro and compared to the effect of non-tumorigenic liver fibroblasts (Lfs). The increased proliferation effect of Cfs having high $\alpha$-SMA on H-69 and 4 CCA cell lines compared to Lfs that expressed low $\alpha$-SMA was observed. Cell cycle analysis indicated that $\mathrm{Cf}$-derived conditioned-medium and direct $\mathrm{Cf}$-epithelial cell contaction could drive epithelial cells into $\mathrm{S}+\mathrm{G} 2 / \mathrm{M}$ phases. These results indicate that fibroblasts in CCA stroma express high $\alpha$-SMA and can be a prognostic indicator for poor patient survival. CCA fibroblasts have proliferative effects which may directly effect tumor promotion and progression of biliary epithelial cells. This warrants further investigation of fibroblasts as alternative therapeutic targets in CCA patients.
\end{abstract}

Correspondence to: Dr C. Thuwajit, Department of Immunology, Faculty of Medicine Siriraj Hospital, Mahidol University, Bangkok 10700, Thailand

E-mail: cthuwajit@yahoo.com

Key words: cholangiocarcinoma, fibroblast, $\alpha$-smooth muscle actin, survival time, cell proliferation

\section{Introduction}

Carcinomas develop from cells of epithelial origin that have undergone genetic mutations and consequently result in the dysregulation of normal growth-controlling mechanisms. Research on the genesis of several carcinomas has been focused mainly on the study of tumor cells and considered the tumorigenesis as an independent process governed by the genes carried within the cancer cells themselves. However, changes in tumor stromal cells surrounding the epithelial malignancy have been observed (1). Tumor stroma is composed mainly of fibroblasts with a minority of inflammatory, smooth muscle and endothelial cells. Changes in these stromal cells have been postulated to enhance several tumorigenic phenotypes of the epithelial cells. It is well accepted that epithelial and stromal cells exchange a reciprocal molecular dialogue that ensures organ homeostasis for proper development and function $(2,3)$. Malignant transformation of epithelial cells disrupts such homeostasis causing changes in tissue architecture, adhesion, cell death and proliferation.

Cholangiocarcinoma (CCA), a carcinoma of bile duct epithelium, is a serious health problem in South Asian countries including Thailand, Lao People's Democratic Republic, Vietnam, Cambodia and South China (4). Moreover, the incidence of CCA has been reported to be increasing in America and Europe $(5,6)$. In Thailand the endemic area of CCA is in the Northeastern part of the country which strongly relates to the high incidence of a liver fluke, Opisthorchis viverrini infection (7). While in Korea or Japan, the risk factor for CCA is Clornorchis sinesis infection (8). In Western countries, the genesis of CCA does not correlate with a liver fluke infection but is associated with chronic inflammation of the bile duct from a variety of etiologies such as sclerosing cholangitis, choledochal cysts and congenital hepatic fibrosis (9-11). Despite the different causes of CCA, it is well recognized that CCA contains abundant fibrous stroma whereas hepatocellular carcinoma has little fibrous tissue (12). Fibrous stromal cells are $\alpha$-smooth muscle actin ( $\alpha$-SMA) positive and their numbers in CCA 
show a significant positive correlation with the degree of tumor fibrosis (13). However, there has been no direct evidence that the level of $\alpha$-SMA expression in CCA fibroblasts has an impact on either the prognosis or the genesis of this cancer.

Studies of fibroblasts in several tumor types support a role of stromal cells in carcinogenesis (14-16). Fibroblasts with $\alpha$-SMA expression can also be called activated fibroblasts or myofibroblasts which are the main cellular constituents of reactive stroma in solid tumors and metastases (17). These cancer-associated fibroblasts have been proposed to give a significant impact on the progression of adjacent malignant epithelia. Myofibroblasts in cancer are defined by not only the expression of $\alpha$-SMA, but also fibroblast activated protein and many other proteins $(18,19)$. Detection of $\alpha$-SMA in cancer stroma has been investigated in many cancer types, and was proposed to have an association with an aggressive phenotype of cancer cells $(20,21)$. Moreover, cumulative evidence suggests that the degree of activated fibroblasts influence the outcome of disease.

Epithelial-fibroblast interaction has been investigated in many carcinomas and revealed the important role of activated fibroblasts in the promoting action on tumor progression and metastasis $(14,15,22-27)$. In particular, surrounding stromal cells can release growth factors, extracellular matrix proteins and angiogenic factors. Carcinogenic effects induced by cancer-associated fibroblasts have been demonstrated in in vitro models of a variety of carcinomas including prostate, breast, colon, head and neck cancers (22-25). A study by Olumi et al showed the prostate cancer cell proliferation induced by the capability of fibroblasts to produce growth factors (22). Stromal changes at the invasion front of cancers, mainly the appearance of myofibroblasts, drove tumor invasion (26). Moreover, fibroblast-induced angiogenesis by the production of angiogenic factors has been reviewed in several cancers (27). In cholangiopathic conditions, portal fibroblasts in ligation-induced bile duct-injured rats induced biliary epithelial cell proliferation (28). However, in our review of the literature, there was no direct evidence of the effects of fibroblasts in CCA stroma on human biliary epithelial cells.

Collectively, it is of great interest to study the characteristic of CCA-associated fibroblasts (Cfs) and their clinical relevance, especially in their ability to help determine the prognosis of CCA patients. In addition, the effect of Cfs on biliary epithelial cells is elaborated to explain the roles of fibroblasts in cholangiocarcinogenesis. In the present study, we investigated the expression of $\alpha$-SMA in CCA tissues and studied the association of its level to the clinicopathological data. In this in vitro study, we isolated and characterized Cfs compared to normal liver fibroblasts (Lfs). The co-culture of Cfs with human biliary epithelial cell lines was performed to assess growth-modulating effects of the fibroblasts on biliary epithelial cells. The impact of activated fibroblasts with high $\alpha$-SMA as a prognostic marker and their potential roles in the genesis of CCA is discussed.

\section{Materials and methods}

Cell lines. The H-69 cell line, was used as a representative of non-tumorigenic biliary epithelial cells. It is a SV40 large-T- antigen infected normal biliary epithelial cell line which could induce cells to be immortal. Four CCA cell lines KKU-M213 and KKU-OCA17, well differentiated; KKUM214, moderately differentiated and KKU-100, poorly differentiated, were kindly donated by Dr Banchob Sripa, Department of Pathology, Faculty of Medicine, Khon Kaen University. H-69 cells were maintained in enriched Dulbecco's minimum essential medium (DMEM) (Gibco, Invitrogen, Carlsbad, CA, USA) containing $10 \%(\mathrm{v} / \mathrm{v})$ fetal bovine serum (FBS) (Gibco, Invitrogen), $100 \mathrm{U} / \mathrm{ml}$ penicillin (Gibco, Invitrogen), $100 \mu \mathrm{g} / \mathrm{ml}$ streptomycin (Gibco, Invitrogen), $25 \mu \mathrm{g} / \mathrm{ml}$ adenine (Sigma, St. Louis, MO, USA), $5 \mu \mathrm{g} / \mathrm{ml}$ insulin (Gibco, Invitrogen), $1 \mu \mathrm{g} / \mathrm{ml}$ epinephrine (Sigma), $13.6 \mathrm{ng} / \mathrm{ml}$ T3T triiodo-L-thyronine (T3) (Sigma), $8.3 \mu \mathrm{g} / \mathrm{ml}$ holo-transferrin (Gibco, Invitrogen), $0.62 \mu \mathrm{g} / \mathrm{ml}$ hydrocortisone (Sigma) and $10 \mathrm{mg} / \mathrm{ml}$ epidermal growth factor (EGF; CytoLab Ltd., Rohovot, Israel). All CCA cell lines were grown in DMEM supplemented with $10 \%(\mathrm{v} / \mathrm{v})$ FBS and incubated in a $5 \% \mathrm{CO}_{2}$ incubator at $37^{\circ} \mathrm{C}$. Cells with passage of less than 10 and more than $90 \%$ viability measured by trypan blue staining were eligible to use in the experiments.

Patients and clinical data for $\alpha$-SMA immunohistochemical analysis. From January 1998 to December 2002, resected specimens from patients with CCA attending the Liver Fluke and Cholangiocarcinoma Research Center, Khon Kaen University, Thailand, were obtained. Necessary ethical clearance was obtained from the institute's ethics committee. Informed consent was obtained from each patient before surgery was performed.

Medical records of each patient were retrieved and 5-year survival was ascertained from these records. Patients who died within 1 month of surgical intervention were excluded from the study. The demographic, clinical, and macroscopic status documented during surgery in each patient were recorded. Definite diagnosis of CCA and metastasis staging were based on histopathological examination. Some lymph nodes were removed during surgery for staging determination. Tumor size was assessed as the largest diameter in the fresh specimen. Distance from the main tumor and lymph node metastases were recorded in surgical and pathological reports. Staging was defined using the TNM system and classified as stage I-IV (29,30). Stage IV was determined as the metastatic stage. Histological classification was based on the criteria of the WHO (29).

CCA tissue sections and immunohistochemistry for $\alpha-S M A$. We randomly selected 55 tissues from CCA patients who underwent surgery between 1998 and 2002, without knowledge of clinicopathological features. Tissue sections of $4-\mu \mathrm{m}$ thickness were prepared from formalin-fixed paraffinembedded blocks. The sections were deparaffinized with xylene and hydrated through ethanol and water solutions. Antigen retrieval for $\alpha$-SMA was done by boiling with high pressure for $5 \mathrm{~min}$. After pretreatment, the sections were blocked for endogenous peroxidase activity by incubation in $0.5 \%(\mathrm{v} / \mathrm{v})$ hydrogen peroxide in methanol on a shaker for $30 \mathrm{~min}$ and washed briefly in PBS. Non-specific binding was blocked with $5 \%(\mathrm{v} / \mathrm{v})$ normal horse serum for $30 \mathrm{~min}$ in a 
Table I. Primers for RT-PCR used in this study.

\begin{tabular}{lllll}
\hline Gene names & Accession no. & Primers & \multicolumn{1}{c}{ Sequences $\left(5^{\prime} \rightarrow 3^{\prime}\right)$} & Product length (bp) \\
\hline Vimentin & NM_003380 & Forward & CAGGTGGACCAGCTAACCAA & 152 \\
& & Reverse & TGCCAGAGACGCATTGTCA \\
Cytokeratin 7 & NM_005556 & Forward & GATGCTGCCTACATGAGCAA & 160 \\
& & Reverse & GGGAGCGACTGTTGTCCA & 146 \\
$\alpha$-SMA & NM_001613 & Forward & CTGTCTTCCCGTCCATCGT & 150 \\
$\beta_{2}$ m & & Reverse & TCAGGGTCAGGATGCCTCT & \\
& NM_004048 & Forward & CATTCCTGAAGCTGACAGCA & \\
\hline
\end{tabular}

humidified chamber at room temperature. Mouse monoclonal anti-human $\alpha$-SMA IgG (Sigma) was incubated overnight at $4^{\circ} \mathrm{C}$ at the dilution 1:200. HRP-rabbit anti-mouse IgG (Zymed Laboratories, San Francisco, CA, USA) was used as a secondary antibody. Tissue sections were incubated with secondary antibody at the dilution of 1:500 for $30 \mathrm{~min}$ in a humidified chamber at room temperature. After being washed, the sections were reacted with $0.05 \%$ 3,3'-diaminobenzidine tetrahydrochloride (DAB; Sigma) and $0.1 \% \mathrm{H}_{2} \mathrm{O}_{2}$ in $50 \mathrm{~mol} / \mathrm{l}$ Tris- $\mathrm{HCl} \mathrm{pH}$ 7.8. For a negative control, PBS was applied on the section instead of the primary antibody. After development, the slides were counter-stained with Mayer's hematoxylin for $1 \mathrm{~min}$. Finally, the sections were dehydrated through increasing concentrations of alcohol (70,95 and $100 \%$ sequentially). The sections were cleared with xylene three times and were then mounted with permount.

Evaluation of immunohistochemical staining. The levels of $\alpha$-SMA immunohistochemical staining in CCA tissues were evaluated without matching knowledge of any clinical data. The positive intensity of $\alpha$-SMA in vascular smooth muscle cells was used as the reference staining value. The $\alpha$-SMA staining in the fibroblasts within tumor stroma was qualitatively classified into 4 groups based on the assumption of the intensity of $\alpha$-SMA in the fibroblasts when compared to that in vascular smooth muscle cells as follows: grade 0 , no staining of $\alpha$-SMA in CCA stromal fibroblasts; grade +1 , $\alpha$-SMA intensity was much lower than that in the vascular smooth muscle cells; grade $+2, \alpha$-SMA intensity was lower than that in the vascular smooth muscle cells; grade +3 , $\alpha$ SMA intensity equaled to that in the vascular smooth muscle cells. For statistical analysis, the 0 and +1 were categorized as low expression, +2 and +3 as high expression.

Establishment of primary culture fibroblasts. Primary fibroblast cultures of three fibroblasts were established from each patient including, normal skin fibroblasts ( $\mathrm{Sfs}$ ) from leftover specimens at the abdominal incision site, nontumorigenic liver fibroblasts (Lfs) and CCA-associated fibroblasts (Cfs). For Sf primary culture, tissues were minced into 2-3 $\mathrm{mm}^{3}$ fragments and plated onto culture plates containing cultured medium under cover slips for 1 week. Then the cover glasses were removed when Sfs had grown and were observed around the explants. Cells were trypsinized and cultured in DMEM containing 10\% FBS and penicillin/streptomycin as antibacterial agents and amphotericin $\mathrm{B}$ as an antifungal agent. Lfs and Cfs were cultured by the mincing technique (31). Briefly, tissues were washed thoroughly in serum-free Ham F-12 (Gibco, Invitrogen) containing $200 \mathrm{U} / \mathrm{ml}$ penicillin and $200 \mu \mathrm{g} / \mathrm{ml}$ streptomycin for 4 times to remove contaminating blood cells and prevent microbial contaminations. The tissues were then placed in sterile petri dishes and cut into $\sim 1 \mathrm{~mm}^{3}$ in size. Then the tissues were transferred to a new petri dish and minced into $\sim 0.2 \mathrm{~mm}^{3}$ in size. Tissues were minced thoroughly in 20\% FBS containing Ham F-12 with $100 \mathrm{U} / \mathrm{ml}$ penicillin, $100 \mu \mathrm{g} / \mathrm{ml}$ streptomycin and $10 \mathrm{ng} / \mathrm{ml}$ epidermal growth factor (CytoLab Ltd.), namely fibroblastcomplete medium. The remaining large pieces of tissues were removed by centrifugation at $400 \mathrm{~g}$ for $5 \mathrm{~min}$. The cell pellets were washed with $1 \mathrm{X}$ PBS once and resuspended in $5-10 \mathrm{ml}$ of fibroblast-complete medium depending on the size of cell pellet and cultured in a $5 \% \mathrm{CO}_{2}$ incubator at $37^{\circ} \mathrm{C}$. After three or four passages, the obtained cultured cells were confirmed as fibroblasts and non-epithelial cells, using the vimentin and cytokeratin 7 detection.

Semi-quantitative reverse transcription-PCR analysis. RNA extraction from the fibroblasts was performed once the cells had reached about $70 \%$ confluence. Total cellular RNA was prepared using TRIzol reagent (Gibco, Invitrogen) according to the manufacturer's directions. The cDNA was produced by the reverse transcription system using AMV reverse transcriptase (Promega, Madison, WI, USA). Two hundred and fifty microgrames of cDNA were used in the PCR reaction containing 1X PCR buffer, $3.5 \mathrm{mM} \mathrm{MgCl}, 0.2 \mathrm{mM}$ dNTPs, $0.08 \mathrm{U}$ Taq polymerase, 0.5X SYBR-Green, $0.04 \mathrm{mM}$ each forward primer and reverse primer. The sequences of PCR primers used are shown in Table I. To avoid the errors of the amount of input cDNA in each reaction, the expression of B2-microglobulin $\left(ß_{2} \mathrm{~m}\right)$ was measured as the internal control. The RT-PCR reactions were performed in ABI 7500 (Apply Biosystem, CA, USA). The CT obtained from the experimental samples were used to calculate the increases of altered expression level expressed as folds to that of negative control 
by the relative quantification formula $\left(2^{-\Delta \Delta C T}\right)$ as previously reported (32).

Western blot analysis of $\alpha$-SMA. Western blot analysis of $\alpha$-SMA in culture fibroblasts were performed as previously reported (33) with minor modifications. One thousand cells were lysed in a protein lysis buffer containing $62.5 \mathrm{mM}$ Tris- $\mathrm{HCl} \mathrm{pH} 6.8,1.25 \%$ (w/v) SDS and 5\% (v/v) glycerol. The concentration of total proteins extracted was determined for protein assay. The $30 \mathrm{mg}$ of total proteins were separated on $10 \%(\mathrm{w} / \mathrm{v})$ sodium dodecylsulfate-polyacrylamine gel electrophoresis and transferred to a polyvinylidene fluoride membrane (Millipore, Billerica, MA, USA) using the transfer buffer containing $25 \mathrm{mM}$ Tris- $\mathrm{HCl} \mathrm{pH} 8.5,192 \mathrm{mM}$ glycine and $20 \%(\mathrm{v} / \mathrm{v})$ methanol in a semidry blotter (Semi-phor ${ }^{\mathrm{TM}}$, Hoefer Scientific Instrument) at $12 \mathrm{~mA}$ for $90 \mathrm{~min}$. Membranes were then placed in the blocking solution containing $5 \%(\mathrm{w} / \mathrm{v})$ skim-milk, $150 \mathrm{mM} \mathrm{NaCl}$ and $6 \mathrm{mM}$ Tris, $\mathrm{pH} 7.4$ at $4^{\circ} \mathrm{C}$ overnight to prevent non-specific binding. The membrane was incubated overnight at $4^{\circ} \mathrm{C}$ with mouse anti- $\alpha$-SMA IgG (Sigma) (dilution 1:200) as the first antibody. Anti-mouse IgG conjugated with HRP (Zymed Labolatories, San Francisco, CA, USA) (dilution 1:500) as the secondary antibody was added to the membrane and incubated at room temperature for $1 \mathrm{~h}$. The expression of proteins was detected by enhanced chemiluminescence (ECL) system (Pierce, Rockford, IL, USA). The detection of $B$-actin expression was used as an internal control. The intensity of bands obtained from Cfs was compared to those from Sfs and Lfs. For re-probing the membranes, the first and second antibodies were removed by incubating the membranes for $1 \mathrm{~h}$ at $65^{\circ} \mathrm{C}$ in stripping buffer containing $0.2 \mathrm{M}$ glycine- $\mathrm{HCl} \mathrm{pH} 2.5,0.05 \%(\mathrm{v} / \mathrm{v})$ Tween-20 and $0.1 \mathrm{M}$ ß-mercaptoethanol.

Conditioned-medium cell proliferation assay. Conditionedmedium $(\mathrm{CM})$ of all fibroblasts were collected by growing fibroblasts in fibroblast-complete medium for 2 days until cells reached about $80 \%$ confluency. Then cells were washed twice with $1 \mathrm{X}$ PBS and twice with $1 \%$ (v/v) FBS-Ham F-12 and incubated for $48 \mathrm{~h}$. After that, CMs were collected, centrifuged at $1,000 \mathrm{~g}$ for $10 \mathrm{~min}$ to remove cell debris, sterile filtered and stored at $-80^{\circ} \mathrm{C}$ until used.

For the CM cell proliferation assay, either the H-69 cell line or CCA cell lines were plated in 96-well plates and then allowed to settle down in $10 \%$ (v/v) FBS-Ham F-12 for 2 days. A $1 \%$ (v/v) FBS-Ham F-12 was added and incubated for $12 \mathrm{~h}$ to keep them at the G1-arrest point. Then Cf-CM, Lf-CM and Sf-CMs were added and incubated for 2 days; $1 \%(\mathrm{v} / \mathrm{v})$ FBS-Ham F-12 was added as a negative control. After incubation, viable epithelial cells were counted using the MTS assay according to the manufacturer's instructions (Promega). Briefly, $20 \mu 1$ of MTS solution reagent was added into each well containing $100 \mu 1$ of culture medium. Then, the plates were incubated for $2 \mathrm{~h}$ at $37^{\circ} \mathrm{C}$ in a $5 \% \mathrm{CO}_{2}$ incubator. The amount of soluble formazan produced by cellular reduction of the MTS was measured by adding $25 \mu 1$ of $10 \%$ $(\mathrm{w} / \mathrm{v})$ SDS to each well to stop the reaction. The absorbance at $490 \mathrm{~nm}$ using an ELISA reader was measured and converted to the number of viable cells by comparing to the standard curve. The number of viable epithelial cells after treatment with $\mathrm{Cf}-\mathrm{CM}$ was compared to those of treatment with Lf-CM and Sf-CM. The number of viable cells cultured in $1 \%(\mathrm{v} / \mathrm{v})$ FBS-medium was used as a reference value for comparison. The statistical significance was analyzed by t-test.

Cell cycle analysis of biliary epithelial cells treated with Cf-CM was performed under flow cytometry after propidium iodide (PI) staining (Gibco, Invitrogen). Epithelial cells treated with each type of CM were trypsinized and about 1 to $5 \times 10^{6}$ cells were collected. Then the cell pellet was obtained by centrifugation at $400 \mathrm{~g}$ for $5 \mathrm{~min}$ and washed with $1 \mathrm{X}$ PBS. Cold $70 \%(\mathrm{v} / \mathrm{v}) \mathrm{EtOH}$ was added and chilled at $4{ }^{\circ} \mathrm{C}$ for at least $4 \mathrm{~h}$, or if needed, at $-20^{\circ} \mathrm{C}$ for long time storage. The suspension was centrifuged at $400 \mathrm{~g}$ for $5 \mathrm{~min}$ to remove all of the supernatant. One hundred microlitres of 1X PBS containing $0.2 \mu 1$ of $50 \mathrm{mg} / \mathrm{ml}$ DNase-free RNaseA (Amresco, Solon, $\mathrm{OH}, \mathrm{USA}$ ) were added and incubated in a $37^{\circ} \mathrm{C} \mathrm{CO}_{2}$ incubator for $30 \mathrm{~min}$. Cell pellets were collected after centrifugation. Finally, $50 \mu \mathrm{l}$ of $1 \mu \mathrm{g} / \mathrm{ml}$ PI solution was added and incubated with protection from light for at least $30 \mathrm{~min}$. Cells were then analyzed for their distribution in the cell cycle by flow cytometry (Cytomic 500, Beckman Counter, Fullerton, CA, USA). The distribution of cells in each stage of the cell cycle was determined. Numbers of epithelial cells in S+G2/ $\mathrm{M}$ phases of the cell cycle were measured in the condition of treatment with $\mathrm{Cf}-\mathrm{CM}$ compared to those of treatment with Lf-CM and Sf-CM. The cell cycle status of cells treated in serum starved medium containing $1 \%(\mathrm{v} / \mathrm{v})$ FBS was used as a negative control. These experiments were repeated three times in replicate culture dishes in the same experiments.

Contact co-culture of fibroblasts and biliary epithelial cells. To study the contact co-culture effect of fibroblasts on biliary epithelial cells, fibroblasts were grown in confluence, and biliary epithelial cells were then layered on top. A green fluorescent dye, CMFDA (5-chloromethyfluorescein diacetate, green fluorescent chloromethyl derivatives of fluorescein diacetate) (Gibco, Invitrogen), was used to stain the fibroblast population adhered on the culture plates prior to addition of the unstained biliary epithelial cells. Fluorescent microscopy as well as flow cytometry easily distinguished the CMFDAstained fibroblasts from the unstained epithelial cells and allowed separation of populations which then could proceed to the analysis of the cell cycle distribution. This procedure was followed with minor modification of that previously reported (22). Briefly, $10^{5}$ of each primary culture fibroblasts were grown to confluence in 6-well plates in fibroblastcomplete medium for a 2-day period. CMFDA staining was accomplished by incubation in $1 \%$ (v/v) FBS-Ham F-12 containing $5 \mu \mathrm{M}$ CMFDA, $100 \mathrm{U} / \mathrm{ml}$ penicillin, and $100 \mathrm{mg} /$ $\mathrm{ml}$ streptomycin for $45 \mathrm{~min}$ at $37^{\circ} \mathrm{C}$. Subsequently, the medium was aspirated, and the fibroblasts were washed twice with serum-free Ham F-12 and further incubated with $10 \%$ (v/v) FBS-Ham F-12 for $1 \mathrm{~h}$. Then, epithelial cells growing in serum-free Ham F-12 for $24 \mathrm{~h}$ to keep them in the G1-arrest condition, were released from the tissue culture plate by trypsinization, and $10^{5}$ cells were reconstituted with $1 \%(\mathrm{v} / \mathrm{v})$ FBS-Ham F-12 and then were plated on the CMFDA-stained fibroblasts. The co-culture between fibroblasts and biliary epithelial cells was performed for 4 days. Co-cultured fibro- 

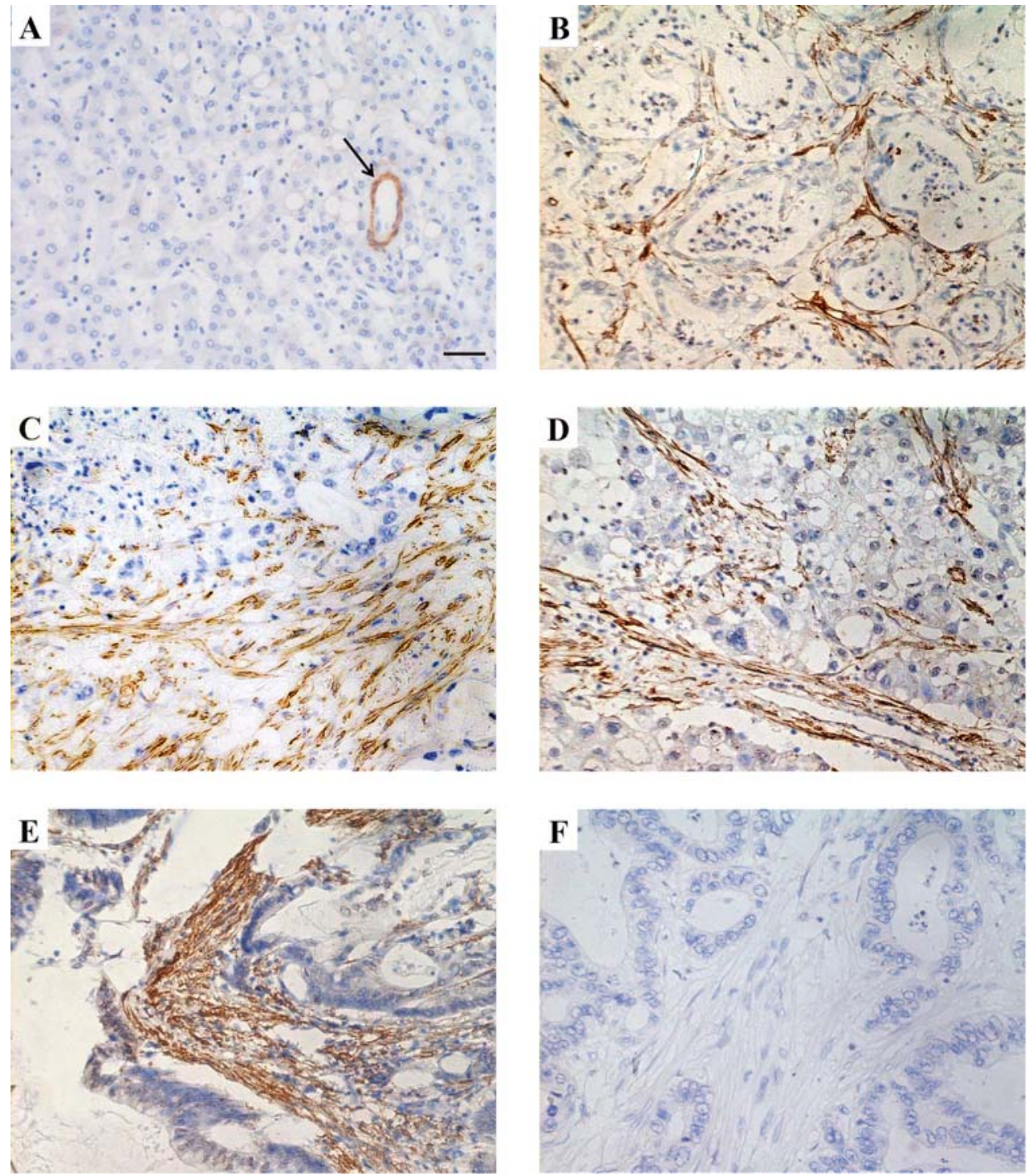

Figure 1. Immunohistochemical staining for $\alpha$-SMA comparing a section of non-cancerous liver tissue (A) and CCA tissues (B-E). The staining of $\alpha$-SMA classified as grade +3 in differently differentiated CCA tissues was demonstrated; well differentiated adenocarcinoma (B); moderately differentiated adenocarcinoma (C); poorly differentiated adenocarcinoma (D); papillary adenocarcinoma (E). A negative control without primary antibody is shown (F). Arrow represents the positive $\alpha$-SMA staining of vascular smooth muscle cells (A). Bar $=\sim 10 \mu$ m. (Magnification x200).

blasts and biliary epithelial cells were together trypsinized. Only PI-stained epithelial cells, but not dual dye-stained fibroblasts, were analyzed to determine the number of viable cells and their cycle distribution pattern under flow cytometry as was performed and mentioned earlier in CM cell proliferation assay.

Statistical analysis. Statistical analysis was performed using SPSS software version 14.0 (SPSS Inc., Chicago, IL, USA). Comparison of low- and high-grade expression of $\alpha$-SMA was performed between stratified age groups ( $\leq 57$ years and $>57$ years), gender, stage of tumor (stage I-III and stage IV), size of tumor $(\leq 5 \mathrm{~cm}$ and $>5 \mathrm{~cm}$ ) and various histological types using Fisher's exact test. A Kaplan-Meier curve was plotted and the log-rank test was used to determine the statistical significance of 5-year survival. For statistical analysis of other experiments including viable cell counts and level of gene expression, t-test analysis was used. P-values of $<0.05$ were considered statistically significant.

\section{Results}

Increased expression of $\alpha$-SMA in CCA tissues. The positive staining of $\alpha$-SMA in non-cancerous liver tissue was identified in vascular smooth muscle cells but not stromal fibroblasts (Fig. 1). The expression of $\alpha$-SMA was observed in fibroblasts of the cancerous area with no staining signals from CCA cells. Despite the different pattern of fibroblasts in the variously differentiated CCA tissues, almost all fibroblasts embedded in the CCA stroma were $\alpha$-SMA positive. In well differentiated tissue, fibroblasts surrounded the relatively uniform CCA lobules, while $\alpha$-SMA positive fibroblasts in moderately and poorly differentiated tissue sections appeared to invade nearly all of the CCA cells because of the distorted tubular patterns. Though nearly all stromal fibroblasts were $\alpha$-SMA positive, the intensity of staining in fibroblasts of each section was compared to that of vascular smooth muscle cells and graded from 0-3 as described in Materials and methods. Despite the different intensities of staining, around 
Table II. The correlation between $\alpha$-SMA expression with clinical data including age, gender, tumor size, tumor staging, histological type, vascular invasion and lymph node metastasis.

\begin{tabular}{|c|c|c|c|c|c|}
\hline Characteristics & Category & $\mathrm{n}$ & High & Low & P-value \\
\hline \multirow[t]{2}{*}{ Age (years) } & $\leq 57$ & 28 & 17 & 11 & 1.000 \\
\hline & $>57$ & 27 & 16 & 11 & \\
\hline \multirow[t]{2}{*}{ Gender } & Male & 34 & 21 & 13 & 0.782 \\
\hline & Female & 21 & 12 & 9 & \\
\hline \multirow[t]{2}{*}{ Tumor size $(\mathrm{cm})$} & $\leq 5$ & 20 & 7 & 13 & $0.009^{*}$ \\
\hline & $>5$ & 35 & 26 & 9 & \\
\hline \multirow[t]{2}{*}{ Tumor staging } & I-III & 10 & 6 & 4 & 1.000 \\
\hline & IV & 45 & 27 & 18 & \\
\hline \multirow[t]{4}{*}{ Histological type } & WD & 23 & 13 & 10 & 0.782 \\
\hline & MD & 9 & 7 & 2 & 0.289 \\
\hline & $\mathrm{PD}$ & 8 & 5 & 3 & 1.000 \\
\hline & Pap & 15 & 8 & 7 & 0.553 \\
\hline \multirow[t]{2}{*}{ Vascular invasion } & Present & 12 & 6 & 6 & 0.512 \\
\hline & Absent & 43 & 27 & 16 & \\
\hline \multirow[t]{2}{*}{ Lymph node metastasis } & Present & 14 & 12 & 2 & 1.000 \\
\hline & Absent & 41 & 21 & 20 & \\
\hline
\end{tabular}

WD, well differentiated; MD, moderately differentiated; PD, poorly differentiated; Pap, papillary; ${ }^{*} \mathrm{P}<0.05$.

$98 \%$ of total cases were $\alpha$-SMA positive. Hence, tissues with $\alpha$-SMA intensity less than a positive control (vascular smooth muscle cells) (grade 0 to +1 ) were classified as low expression, whereas those with $\alpha$-SMA intensity more than a positive control (grade +2 to +3 ) were classified as high expression.

Correlation of $\alpha$-SMA expression with clinical presentation. Resected specimens from 55 consecutive patients, 34 were male and 21 were female with a male to female ratio of 1.6:1 (Table II). Their median age was 57 years (range, 28-72 years). The comparisons of expression of $\alpha$-SMA between age groups, gender, tumor size, tumor staging, histological type, vascular invasion and lymph node metastasis are shown in Table II. The expression of $\alpha$-SMA was similar between, age groups, sexes, tumor staging, various histological types, vascular invasion and lymph node metastasis $(\mathrm{P}>0.05)$. However, high $\alpha$-SMA expression was documented significantly more often in tumor sizes of $>5 \mathrm{~cm}(74 \%, 26$ of 35 cases $)$ than of tumors $\leq 5 \mathrm{~cm}(35 \%, 7$ of 20 cases $)$ $(\mathrm{P}=0.009)$.

Expression of $\alpha$-SMA correlates with the survival time. Survival analysis was performed in 52 patients (out of a total of 55 cases) with 5-year follow-up data and excluding the 3 patients with 1-month postoperative period deaths possibly caused by surgical complications. The results showed that 31 patients $(60 \%)$ had high expression levels of $\alpha$-SMA, whereas

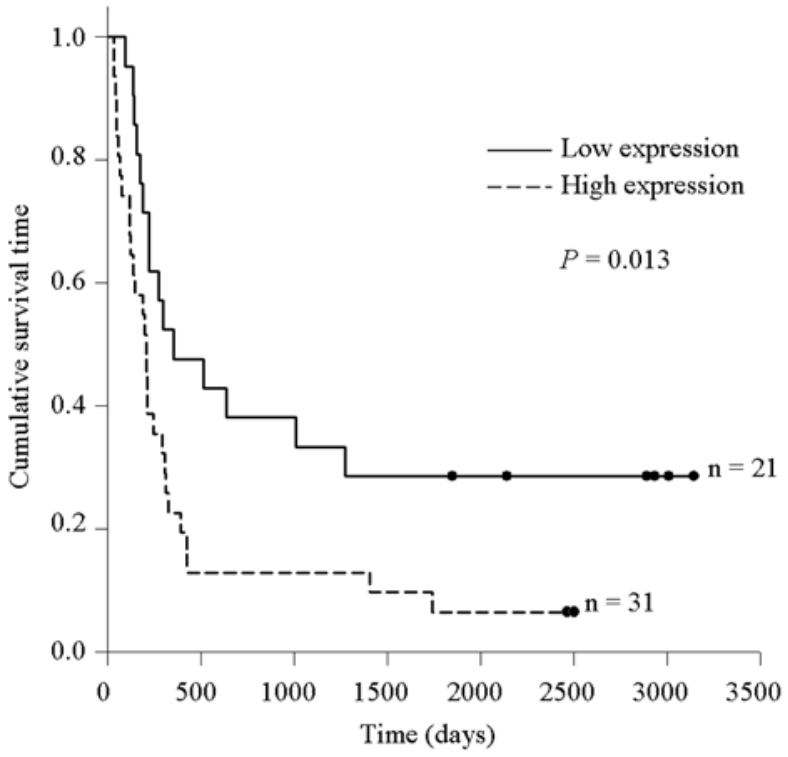

Figure 2. The survival curve using Kaplan-Meier method. Survival time of patients with tumors having a high expression of $\alpha$-SMA as opposed to patients having low expression tumors is shown. The dots indicate patients who survived $>5$ years.

the other 21 patients (40\%) had low expression levels (Fig. 2). Five-year survival in the former and latter was $6 \%(2 / 31)$ and $29 \%(6 / 21)$ respectively $(\mathrm{P}=0.013)$. Analysis for the correlation 
A

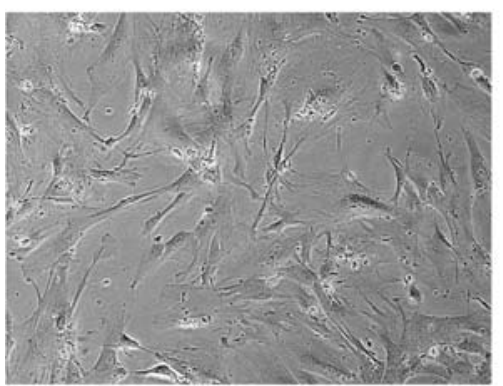

Lf

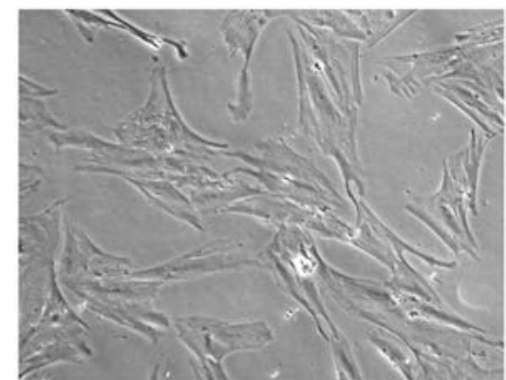

Sf

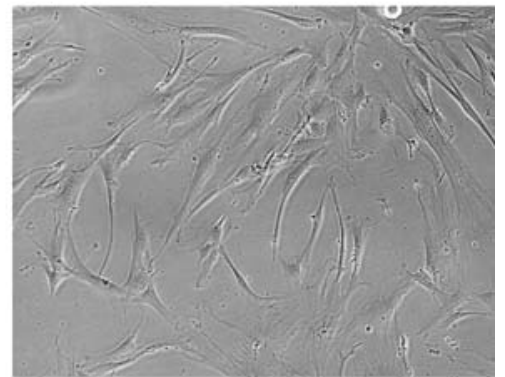

B

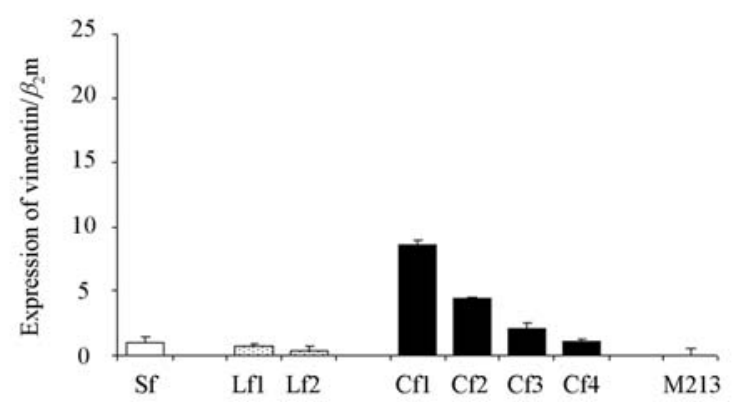

C

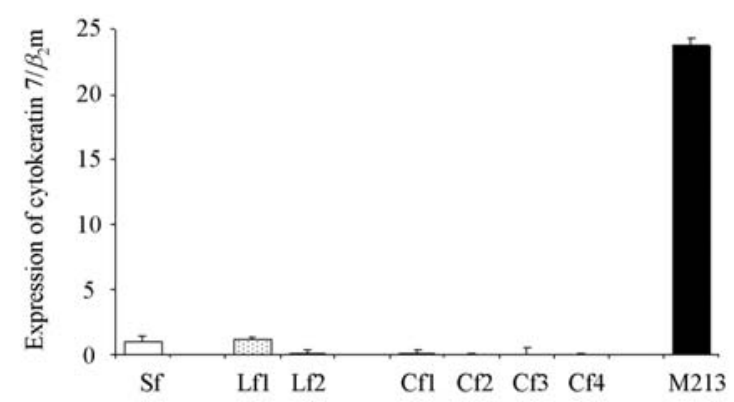

Figure 3. Primary culture fibroblasts from CCA patients including CCA-associated fibroblasts (Cf), non-tumorigenic liver fibroblast (Lf), and skin fibroblast (Sf) (A). (Magnification x100). The spindle-like shape was observed in all three types of fibroblasts. Semi-quantitative RT-PCR of cell specific markers including vimentin (B) and cytokeratin 7 (C), in primary culture fibroblasts is shown. The same number represents the identical patients from whom the primary culture fibroblasts were harvested. The expression of $\beta_{2} m$ was used to normalize the amount of cDNA template in each sample. The expression levels in Sf and M213 CCA cell line were used as the positive controls for vimentin and cytokeratin 7 , respectively. The values shown represent the mean \pm SD of three experiments.

between $\alpha$-SMA expression and survival time showed that 31 $(60 \%)$ of the patients who had high expression had a median survival of 205 days and the remaining 21 (40\%) with low expression had a median survival of 358 days.

Primary culture fibroblasts expressed a high level of $\alpha$-SMA and vimentin. We established primary culture fibroblasts from three tissue sources of CCA patients; Sfs from the abdominal incision areas of the patients having undergone hepatectomy, Lfs from a distant area of CCA mass embedded in the hepatectomized liver; and Cfs from tumorigenic area of CCA tissues. The morphology of all primary culture fibroblasts was a spindle-like shape (Fig. 3A).

Real-time PCR for vimentin, a fibroblast marker, demonstrated that all of the primary culture fibroblasts had a certain level of expression more than that of the M213 CCA cell line used as a negative control (Fig. 3B). The expression of vimentin in $\mathrm{C}$ fs showed at a higher level than that observed in Lfs and Sfs and even in different Cfs. We also confirmed the absence of epithelial biliary cell contamination in the primary fibroblast culture by measuring the expression of the cytokeratin-7 epithelium-specific marker. The result revealed a slight expression of cytokeratin-7 in all primary culture fibroblasts compared to that of M213 CCA cell lines used as a positive control (Fig. 3C). To characterize whether these primary culture fibroblasts were activated fibroblasts as detected in CCA tissues, real-time PCR of $\alpha$-SMA was performed. The results revealed that $\mathrm{Cfs}$ had significantly higher expression level of $\alpha$-SMA than those of Lfs, whereas
A

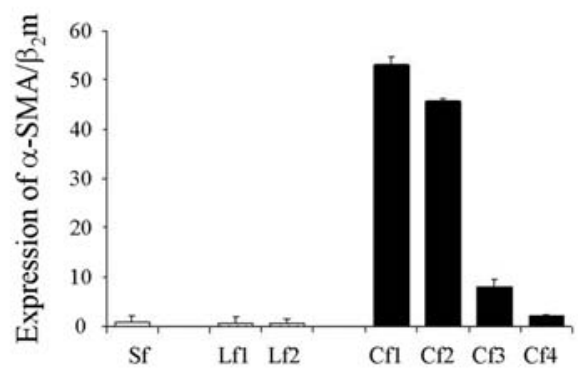

B

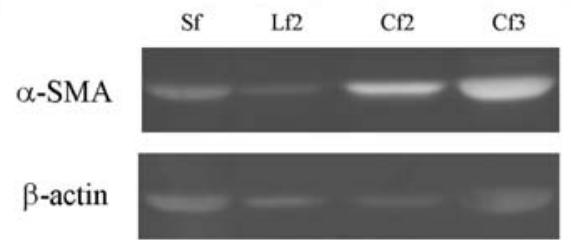

Figure 4. Detection of $\alpha$-SMA in different primary culture fibroblasts by real-time RT-PCR (A) and Western blot analysis (B). Cfs and Lfs from different CCA patients was studied. The same number represents the identical patients from whom the primary culture fibroblasts were harvested. The values shown represent the mean $\pm \mathrm{SD}$ of three experiments. In Western blot analysis, the expression of $\beta$-actin was used as an internal control of a housekeeping gene expression level.

the expression levels of $\alpha$-SMA in Lfs were similar to those of Sfs (Fig. 4A). Western blot analysis revealed higher expression of $\alpha$-SMA in Cfs than in non-tumorigenic fibroblasts (Fig. 4B). 
A

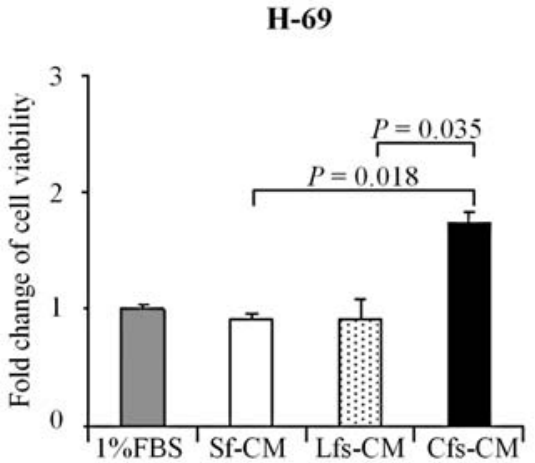

B

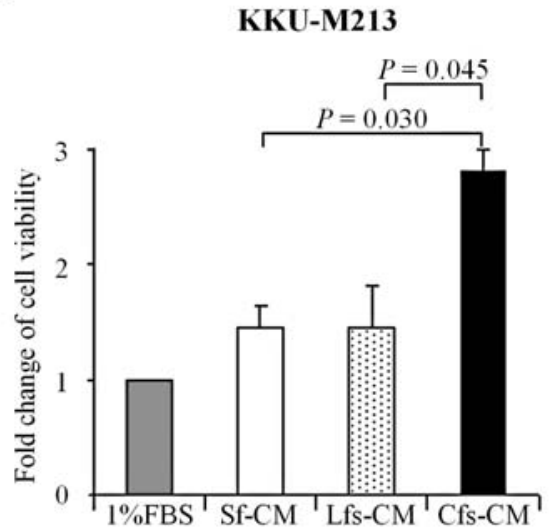

D

KKU-M214

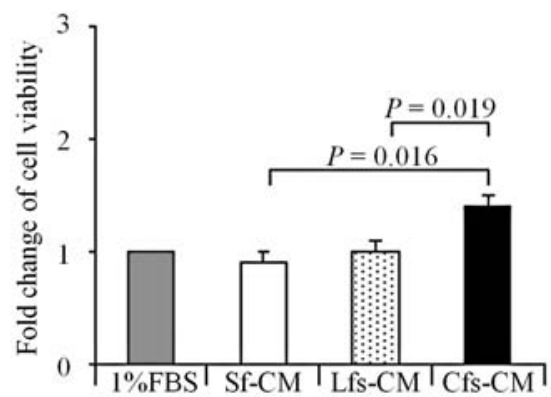

C

KKU-OCA17

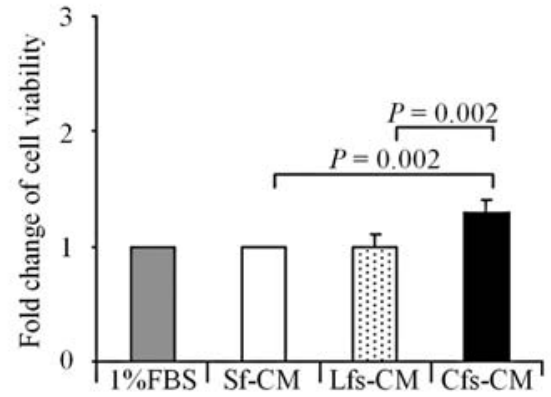

$\mathbf{E}$

KKU-100

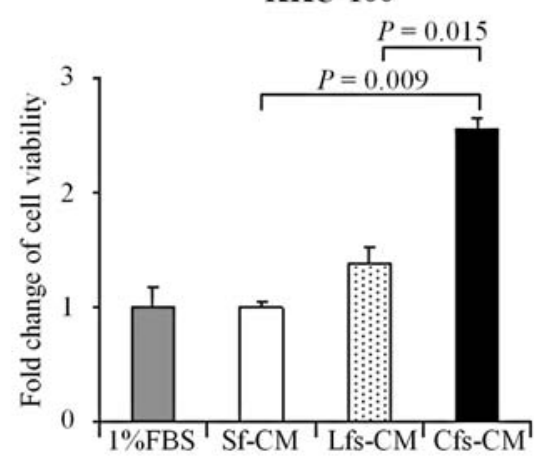

Figure 5. Proliferation effect of fibroblast-derived conditioned-media on different epithelial cells; non-tumorigenic biliary epithelial cells (H-69) (A); and differently differentiated CCA cell lines: well differentiated cell line (KKU-M213) (B), well differentiated cell line (KKU-0CA17) (C), moderately differentiated cell line (KKU-M214) (D), poorly differentiated cell line (KKU-100) (E). Results were indicated as fold change in viable cell number as compared to control medium containing $1 \%(\mathrm{v} / \mathrm{v})$ FBS. Bars represent the mean \pm SD of triplicate experiments.

Cf conditioned-media significantly induced proliferation of biliary epithelial cells. To characterize the fibroblast cultures and compare their putative effect on cancer cells, the biliary epithelial cells of both non-tumorigenic and tumorigenic origin were incubated with different CMs and effects on their proliferation and cell cycle distributions were analyzed. The results revealed a growth-promoting effect on biliary cells with Cf-CM treatment more than Lf-CM and Sf-CM treatments (Fig. 5). The potential of cell proliferation induction as measured by the MTS assay occurred in the following order: $\mathrm{Cf}-\mathrm{CM}>\mathrm{Lf}-\mathrm{CM} \geq \mathrm{Sf}-\mathrm{CM}$. This proliferation effect could be seen both in non-tumorigenic biliary epithelial cells; H-69, and tumorigenic biliary epithelial cells or CCA cell lines with different differentiations.

Cell cycle analysis of biliary epithelial cells after being exposed to Cf-CM indicated increased number of cells in $\mathrm{S}+\mathrm{G} 2 / \mathrm{M}$ phases of the cell cycle in both the H-69 cell line (Fig. 6) and KKU-M213 CCA cell line compared to those either treated with Lf-CM or starved in $1 \%(v / v)$ FBS containing media. The number of cells in treatments with Lf-CM and Sf-CM showed quite similar distribution patterns of cells in the cell cycle. This result showed the potential of $\mathrm{Cf}-\mathrm{CM}$ to induce cell proliferation by driving both nontumorigenic and tumorigenic biliary epithelial cells into 
A

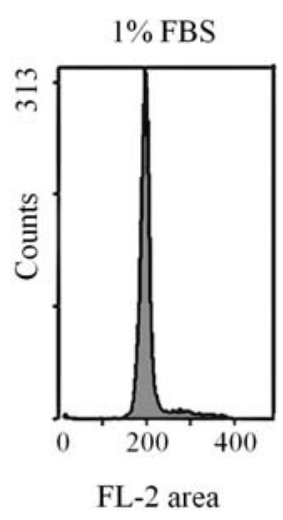

B

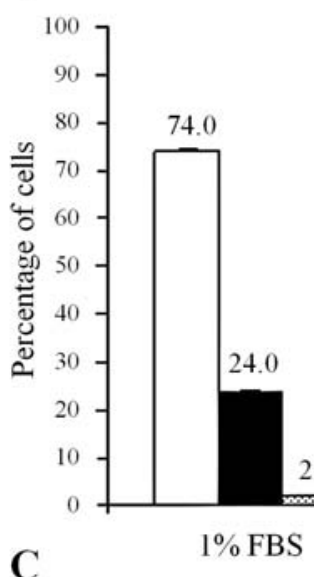

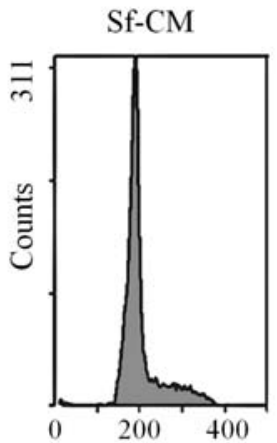

FL-2 area

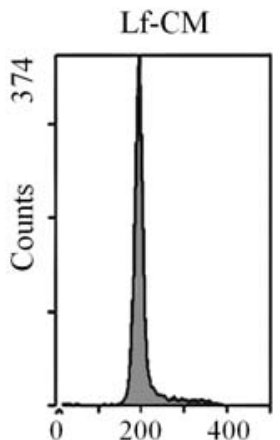

FL-2 area

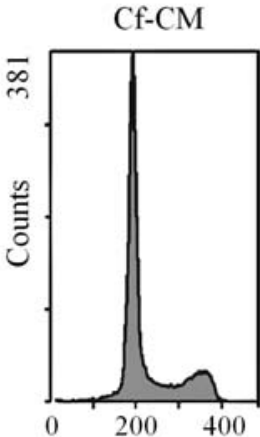

FL-2 area

H-69
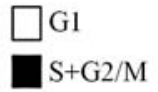

Apoptotic cells

69.3
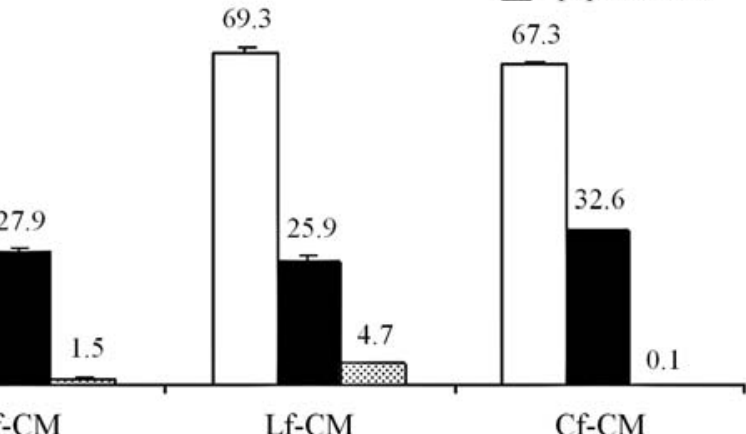

Lf-CM

Cf-CM

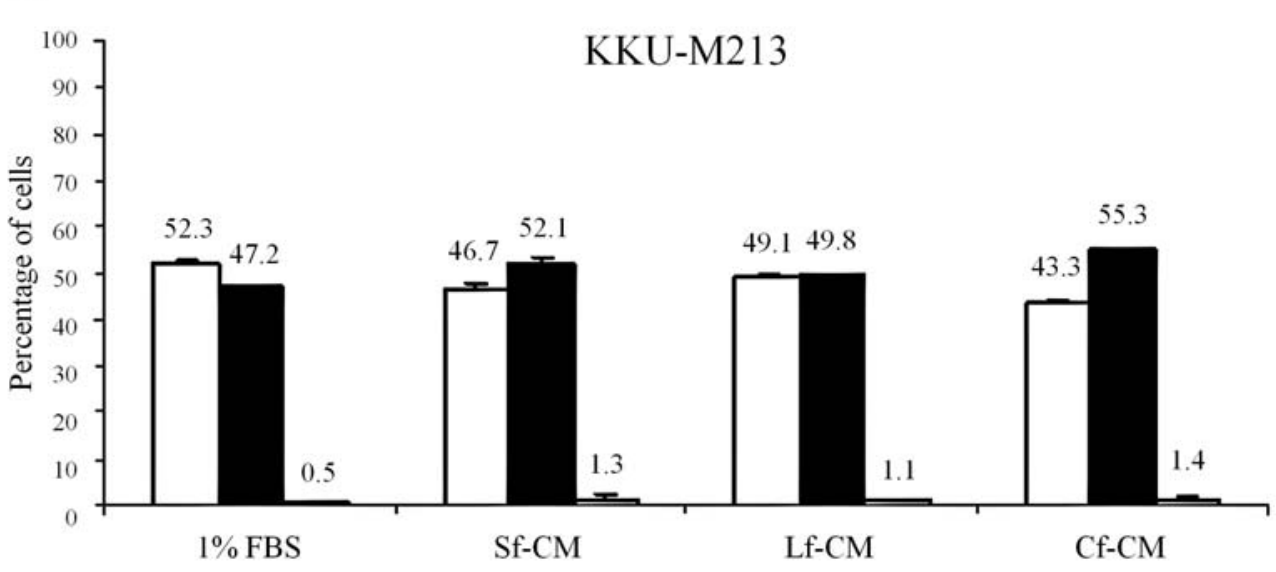

Figure 6. Cell cycle analysis of PI-stained biliary epithelial cells after treatment with different CMs. The cell populations were analyzed for DNA content after PI staining using flow cytometry. The raw data as provided by the FACS machine, which showed the FACS profiles (x-axis, DNA content; y-axis, cell number) of H-69 cell line are shown (A). The cell cycle distribution of the profiles was quantitated and is shown in bar graphs including G1, S+G2/M-phases for H-69 cell line (B) and KKU-M213 cell line (C). G1-arrest cells by culturing in 1\% (v/v) FBS were used as the negative control. A higher percentage of biliary epithelial cells in the S+G2/M phases after treatment with Cf-CM was observed compared to those treated with Lf-CM and Sf-CM. Results are expressed as the means \pm SD of triplicate experiments.

active proliferative stages of cell cycle. Moreover, the result of Cf-CM treated H-69 showed less apoptotic activity than the H-69 cells treated with Sf-CM or Lf-CM (Fig. 6B). However, this result was not seen in the response of the KKU-M213 CCA cell line (Fig. 6C).

Contact co-culture of Cf and biliary epithelial cells increased biliary cell proliferation and activated cells into the active stages of the cell cycle. Primary culture fibroblasts and biliary epithelial cells were cultured together in the cell-to-cell contact mode. The epithelial cells were plated on-top and were not stained with CMFDA. Cell cycle analysis of biliary epithelial cells activated by direct contact with $\mathrm{Cfs}$ revealed more numbers of cells in the proliferative stages of the cell cycle $(\mathrm{S}+\mathrm{G} 2 / \mathrm{M})$ than those contact co-cultured with Lfs and Sfs. This phenomenon could be observed in both H-69 and KKU-100 CCA cell lines (Fig. 7).

\section{Discussion}

Stromal-epithelial interactions can affect tumor progression from pre-neoplasia to neoplasia. Changes in the stromal 
A

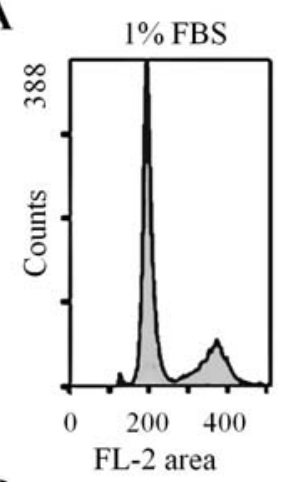

B

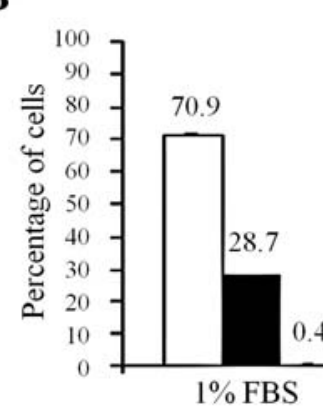

H-69

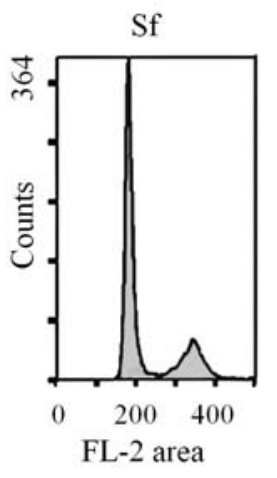

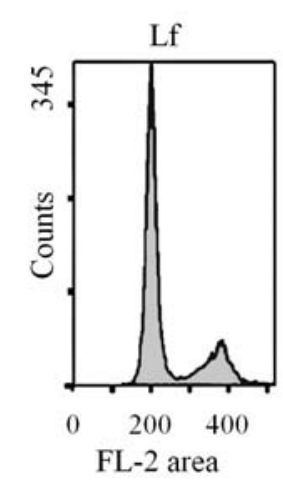
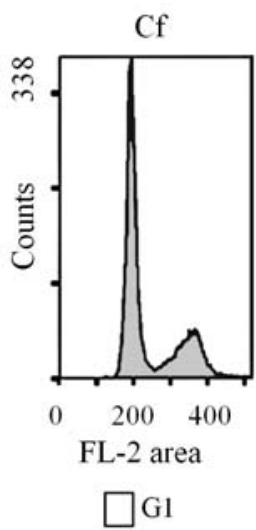

$\mathrm{S}+\mathrm{G} 2 / \mathrm{M}$

66.3

Apoptotic cells

C

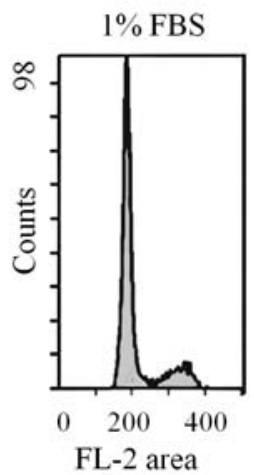

D

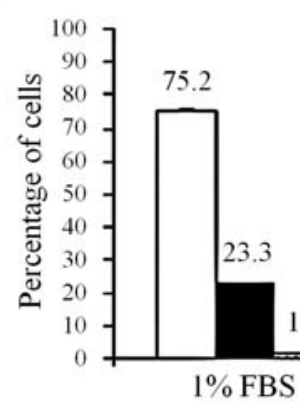

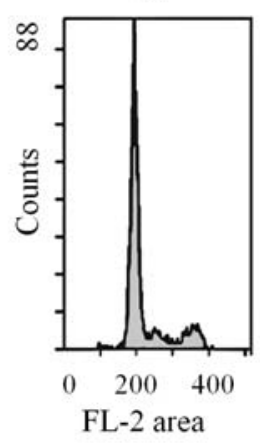

KKU-100
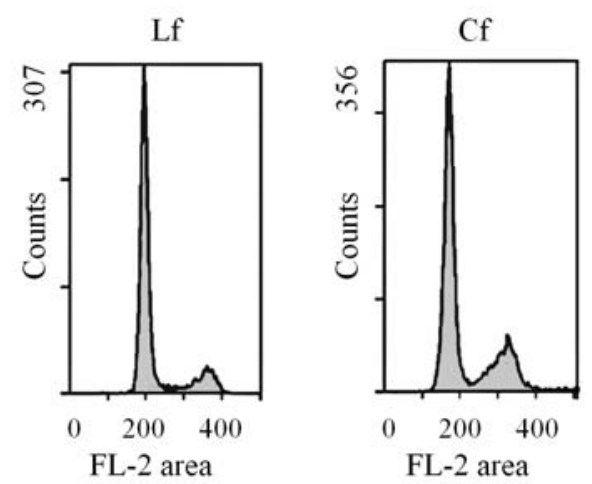

Figure 7. Cell cycle analysis of PI-stained biliary epithelial cells after contact co-culture with different fibroblasts including Sf, Lf and Cf. The cell populations were analyzed for DNA content after PI staining using flow cytometry. The raw data as provided by the FACS machine, which showed the FACS profiles (x-axis, DNA content; y-axis, cell number), are shown for H-69 (A) and KKU-100 (C). The cell cycle distribution was quantitated and is shown in a bar graph including G1, S+G2/M-phases for a non-tumorigenic biliary epithelial cell line (H-69) (B) and KKU-100 (D). Cells cultured in 1\% (v/v) FBS containing medium were used as a negative control. Results are expressed as the means \pm SD of triplicate experiments.

microenvironment, including changes in fibroblasts, endothelial cells, lymphocytes and extracellular matrix, can potentiate tumor promotion and progression in many cancer types (22-27). Though there have been reports on the detection of activated fibroblasts and the consequence of marked fibrosis in CCA $(13,34)$, the possible effect of activated stromal fibroblasts or myofibroblasts and their impact on the genesis and progression of CCA is not well defined. In this study, we demonstrated the presence of myofibroblasts in CCA tissues by immunohistochemistry and its correlation with patient clinicopathological data. The results of $\alpha$-SMA expression indicated a high level of this 
protein only in fibroblasts embedded in CCA stroma (Fig. 1). No $\alpha$-SMA expression was observed in fibroblasts embedded in the adjacent area to the tumor mass; not even in the CCA cells. This result confirmed other previous studies showing that fibroblasts in CCA stroma were $\alpha$-SMA immunoreactive $(13,34)$ and were prominent in the sinusoids surrounding cancer nodules and in the cancerous stroma but not in sinusoids remote from cancer masses (13). Moreover, the number of intratumoral $\alpha$-SMA positive stromal cells showed a significant positive correlation with the amount of cancerous fibrous stroma in CCA (13). However, the correlation of $\alpha$-SMA and the prognosis of CCA patients has not been previously reported. We demonstrated that the level of $\alpha$-SMA expression in CCA fibroblasts correlated with tumor size (Table II) and 5-year survival of the patients with statistical significance (Fig. 2). Patients with high $\alpha$-SMA expression in the stromal fibroblasts tend to have shorter survival times than patients with low $\alpha$-SMA. This may be useful in identifying CCA patients with a poor prognosis. Moreover, in regard to our data, the level of $\alpha$-SMA in CCA fibroblasts correlated with large tumor size with statistical significance (Table II). This implies that CCA fibroblasts may act as a tumor stromal progressing agent in CCA likely by secreting growth promoting factors (22). We conclude that the present data support the notion of CCA fibroblasts as a useful indicator of patient survival, probably by inducing a highly malignant property of cancer cells i.e. increased cell proliferation and decreased apoptosis.

To demonstrate the effect of activated fibroblasts in CCA, we isolated primary culture fibroblasts from fresh CCA tissues, then characterized and studied their biological roles on biliary epithelial cells in vitro. From the review of literature, it was found that some cancer cells responded to fibroblasts by direct physical contact between the cells $(23,35)$ whereas some responded to the secreted substances released from the cancer fibroblasts $(22,24)$ and some responded in both modes (22). Herein, we did the experiments in both contact and noncontact co-cultures between CCA fibroblasts and human biliary epithelial cells. The proliferation, distribution in the cell cycle and apoptotic effects of fibroblast-treated epithelial cells were observed. Firstly, the primary culture fibroblasts including Cfs, Lfs and Sfs were confirmed to be without epithelial cell contamination by the presence of vimentin and the absence of cytokeratin-7 (Fig. 3). Cytokeratin-7 has been proven to be one of the important proteins specifically expressed not only in normal biliary epithelium (36), but also in CCA and liver metastases of extrahepatic bile duct cancer (37). For vimentin, it is ubiquitously expressed by cells of mesenchymal origin including fibroblasts, endothelial cells, smooth muscle cells and some other cells (38). Even though Cfs and Lfs were both fibroblasts, our data showed that the expression of vimentin in Cfs was much higher than in Lfs (Fig. 3B). Moreover, the expression level of vimentin in different Cfs was also observed in the same fashion as that of $\alpha$-SMA expression (Fig. 4A). Since cancer fibroblasts with up-regulation of vimentin were associated with poor patient survival (39), the increased vimentin in Cfs as compared to Lfs found in our study may imply that CCA fibroblasts exhibited a certain phenotype different from that of nontumorigenic liver fibroblasts. This supports the possibility that $\mathrm{Cfs}$ have more tumorigenic functions than Lfs. In concert with the finding in colorectal cancer where vimentin expression was claimed to reflect a higher malignant potential of the tumor, these findings may be useful as a predictive marker for disease recurrence and as a marker of poor prognosis (40). It may imply that CCA patients having cancer fibroblasts with different levels of vimentin may have different prognoses. With the support of further experiments to determine the correlation of vimentin and the prognosis of CCA patients, our findings may suggest the potential to use vimentin expression in CCA stroma fibroblasts as a prognostic indicator.

Portal fibroblasts with the $\alpha$-SMA positive phenotype have been demonstrated to regulate the proliferation of bile duct epithelial cells in cholangiopathology (28). However, no direct evidence on the effect of CCA fibroblasts on biliary epithelial cells has been reported. In our study, primary culture Cfs showed that the activated phenotype had a higher expression of $\alpha$-SMA than that in Lfs and Sf (Fig. 4). In the in vitro non-contact co-culture used herein, the results showed that Cf-CM significantly promoted biliary cell proliferation to a greater extent than that of either Lfs or Sfs (Fig. 5). Cf-CM treatment to the non-tumorigenic biliary epithelial cells (H-69) dramatically stimulated cell proliferation. In addition, the same effect was seen when CCA cell lines were exposed to Cf-CM. This is in agreement with findings in other cancers where substances released from cancer fibroblasts induced epithelial cell proliferation $(22,39)$. Cancer fibroblasts are capable of modulating the phenotypes of nearby epithelial cells through paracrine signaling mechanisms. They have been documented to secrete a variety of growth factors including transforming growth factor- $\beta$, platelet-derived growth factor, insulin-like growth factor I and II, hepatocyte growth factor/epithelial scatter factor, and fibroblast growth factor (41-46). Most of these factors are predominantly stimulators of proliferation which play an important part in promoting the carcinogenic process. For example, the increases in transforming growth factor- $\beta$ expression in breast cancer correlated with the accumulation of fibrotic desmoplastic tissue (47) and increased rate of tumor progression (48). H-69 and CCA cell lines used in this study represent the epithelial cell at different stages of carcinogenesis as follows: H-69 represents cells at the promotion step whereas CCA cell lines represent cells at the progression step. Hence, it may be proposed that Cfs can produce secreted substances which have a proliferative effect on biliary cells of both non-tumorigenic and tumorigenic types, which thus can govern the cholangiocarcinogenesis at both promotion and progression steps. Moreover, the results revealed that $\mathrm{Cf}-\mathrm{CM}$ exhibited the anti-apoptotic effect on the H-69 cell line when compared to that treatment with either Lf-CM or Sf-CM (Fig. 6B). However, this antiapoptotic effect could not be seen in CCA cell lines treated with Cf-CM (Fig. 6C). This observation may be supported with the previous finding that prostate cancer progression was associated with suppression of the apoptosis pathway via the activation of PI(3)K substrate (49). This suppression of apoptosis is an early event occurring at the transition from histological normal epithelium to prostate intraepithelial neoplasia. 
In addition to the conditioned-medium assays, without direct interaction between biliary epithelial cells and fibroblasts, we demonstrated that culturing biliary epithelial cells on the CCA fibroblasts could influence the biliary cell proliferation compared to those cultured on the normal fibroblasts (Fig. 7). Though, this can not exclude the effects of a paracrine effect from fibroblast-derived substances, the role of cell-cell contact to induce some signal transduction pathway-mediated cell proliferation may be considered. The importance of such signals which govern cell proliferation was published in demonstrating serum-activated fibroblasts promoting clonogenic growth of human breast cancer cells (35). In regard to our study, the CM influence on epithelial cells without any contact seems to show more increased biliary epithelial cell proliferation than that of the contact experiment. This may be due to the fact that even fibroblast-epithelial cell contact could induce cell proliferation but at the same time, may elaborate a cell-cell contact inhibition phenomenon that will retard cell proliferation capacity.

In summary, $\alpha$-SMA positive fibroblasts induced proliferation of both non-tumorigenic biliary epithelial cells and CCA cells via both secreted substances and cell-cell contact. It is tempting to speculate that CCA fibroblasts may directly promote and influence progression of cholangiocarcinogenesis. In the early event, fibroblasts may induce the non-tumorigenic epithelial cells to have uncontrolled growth by not only stimulating the entering of cells into the cell cycle, but also by inhibiting apoptosis. In the late stage of carcinogenesis, when biliary epithelial cells are completely transformed to CCA cells, induction of cell proliferation seems to have more effect. The activated fibroblasts have been identified to have the ability to produce many soluble factors and reported to modulate various aspects of tumor progression including proliferation or invasion $(44,50)$, angiogenesis (51) or inhibition of cell death (52).

In light of the evidence presented by us, $\alpha$-SMA expression level should prove beneficial as a predictive marker for the 5-year survival potential of CCA patients. These activated fibroblasts have a critical role to play in the induction of uncontrolled tumor growth and in helping cancer cells to exhibit aggressive malignant behavior that finally attenuates the patient survival time. Regarding the belief that targeting the tumor as an organ would be more effective than targeting the tumor alone, stromal therapy has been proposed to be more flexible and applicable to a wider range of disease stages, as its target is dynamic (53). Furthermore, in hepatocellular carcinoma, chemotherapy was demonstrated to be more effective if therapies against the underlying fibrosis were also employed $(54,55)$. These present experiments support the possibility to further use the fibroblast as a therapeutic target in treatment of CCA patients.

\section{Acknowledgements}

This study was supported by Invitation Grant 2007 (Grant no. i50102), Faculty of Medicine, Khon Kaen University, a Grant of Khon Kaen University 2007, and Thailand Research Fund (RMU5080069). CC was supported by Student Grant, Liver Fluke and Cholangiocarcinoma Research
Center during 2005-2007. The author would like to thank Professor James A. Will (University of Wisconsin-Madison) for editorial comments on the manuscript.

\section{References}

1. Ronnov-Jessen L, Peterson OW and Bissell MJ: Cellular changes involved in conversion of normal to malignant breast: importance of the stromal reaction. Physiol Rev 76: 69-125, 1996.

2. Cunha GR, Alarid ET, Turner T, Donjacour AA, Boutin EL and Foster BA: Normal and abnormal development of the male urogenital tract: role of androgens, mesenchymal-epithelial interactions and growth factor. J Androl 13: 465-475, 1992.

3. Haffen K, Kedinger M, Simon-Assmann PM and Lacroix B: Mesenchyme-dependent differentiation of intestinal brushborder enzymes in the gizzard endoderm of the chick embryo. Prog Clin Biol Res 85: 261-270, 1982.

4. Vatanasapt V, Sripa B, Sithithaworn P and Mairiang P: Liver fluke and liver cancer. Cancer Surv 33: 313-343, 1999.

5. Khan SA, Taylor-Robinson SD, Toledano MB, Beck A, Elliott P and Thomas HC: Changing international trends in a mortality rates for liver, biliary, and pancreatic tumors. J Hepatol 37: 806-813, 2002.

6. Taylor-Robinson SD, Toledano MB, Arora S, et al: Increase in mortality rates from intrahepatic cholangiocarcinoma in England and Wales 1968-1998. Gut 48: 816-820, 2001.

7. Jongsuksuntigul $P$ and Imsomboon T: Opisthorchiasis control in Thailand. Acta Trop 88: 229-232, 2003.

8. Choi D, Lim JH, Lee KT, et al: Cholangiocarcinoma and Clonorchis sinensis infection: a case-control study in Korea. J Hepatol 44: 1066-1073, 2006.

9. Broome U, Olsson R, Loof L, et al: Natural history and prognostic factors in 305 Swedish patients with primary sclerosing cholangitis. Gut 38: 610-615, 1996.

10. Scott J, Shousha S, Thomas HC and Sherlock S: Bile duct carcinoma: a late complication of congenital hepatic fibrosis: case report and review literature. Am J Gastroenterol 73: 113-119, 1980.

11. Lipsett PA, Pitt HA, Colombani PM, Boitnott JK and Cameron JL: Choledochal cyst disease: a changing pattern of presentation. Ann Surg 220: 644-652, 1994.

12. The liver cancer study group of Japan: Primary liver cancers in Japan. Cancer 54: 1747-1755, 1984.

13. Terada T, Makimoto K, Terayama N, Suzuki Y and Nakanuma Y: Alpha-smooth muscle-positive stromal cells in cholangiocarcinomas, hepatocellular carcinomas and metastatic liver carcinomas. J Hepatol 24: 706-712, 1996.

14. Adam L, Crepin M, Lelong JC, Spanakis E and Israel L: Selective interactions between mammary epithelial cells and fibroblasts in co-culture. Int J Cancer 59: 262-268, 1994.

15. Dong-Le Bourhis X, Berthois Y, Millot G, Degeorges A, Sylvi M, Martin PM and Calvo F: Effect of stromal and epithelial cells derived from normal and tumorous breast tissue on the proliferation of human breast cancer cell lines in co-culture. Int $\mathrm{J}$ Cancer 71: 42-48, 1997.

16. Skobe M and Fusenig NE: Tumorigenic conversion of immortal human keratinocytes through stromal cell activation. Proc Natl Acad Sci USA 95: 1050-1055, 1998.

17. Micke P and Ostman A: Exploring the tumor environment: cancer-associated fibroblasts as targets in cancer therapy. Expert Opin Ther Targets 9: 1217-1223, 2005.

18. Ronnov-Jessen L, Peterson OW, Koteliansky VE and Bissell MJ: The origin of the myofibroblasts in breast cancer: recapitulation of tumor environment in culture unravels diversity and implicates converted fibroblasts and recruited smooth muscle cells. J Clin Invest 95: 859-873, 1995.

19. Garrin-Chesa P, Old LJ and Rettig WJ: Cell surface glycoprotein of reactive stromal fibroblasts as a potential antibody target in human epithelial cancers. Proc Natl Acad Sci USA 87: 7235-7239, 1990.

20. Tsujino T, Seshimo I, Yamamoto H, et al: Stromal myofibroblasts predict disease recurrence for colorectal cancer. Clin Cancer Res 13: 2082-2090, 2007.

21. Gregoire M and Lieubeau B: The role of fibroblasts in tumor behavior. Cancer Metastasis Rev 14: 339-350, 1995.

22. Olumi AF, Grossfeld GD, Hayward SW, Carroll PR, Tlsty TD and Cunha GR: Carcinoma-associated fibroblasts direct tumor progression of initiated human prostatic epithelium. Cancer Res 59: 5002-5011, 1999. 
23. Sadlonova A, Novak Z, Johnson MR, et al: Breast fibroblasts modulate epithelial cell proliferation in three-dimensional in vitro co-culture. Breast Cancer Res 7: R46-R59, 2005.

24. Nakagawa H, Liyanarachchi S, Davuluri RV, Auer H, Martin EW Jr, De la Chapelle A and Frankel WL: Role of cancerassociated stromal fibroblasts in metastatic colon cancer to the liver and their expression profile. Oncogene 23: 7366-7377, 2004.

25. Tokumaru Y, Fujii M, Otani Y, Kameyama K, Imanishi Y, Igarashi $\mathrm{N}$ and Kanzaki J: Activation of matrix metalloproteinase2 in head and neck squamopus cell carcinoma: studies of clinical samples and in vitro cell lines co-cultured with fibroblasts. Cancer Lett 150: 15-21, 2000.

26. De Wever O and Mareel M: Role of tissue stroma in cancer cell invasion. J Pathol 200: 429-447, 2003

27. Yang F, Tuxhorn JA, Ressler SJ, McAlhany SJ, Dang TD and Rowley DR: Stromal expression of connective tissue growth factor promotes angiogenesis and prostate cancer tumorigenesis Cancer Res 65: 8887-8895, 2005

28. Jhandier MN, Kruglov EA, Lavoie EG, Sevigny J and Dranoff JA: Portal fibroblasts regulate the proliferation of bile duct epithelia via expression of NTPDase2. J Biol Chem 280: 22986-22992, 2005.

29. Hirohashi S, Blum HE, Ishak KG, et al: Tumours of the liver and intrahepatic bile ducts. In: World Health Organization Classification of Tumours. Pathology and Genetics of Tumours of the Digestive System. Hamilton SR and Aaltonen LA (eds). IARC press, Lyon, pp157-180, 2000.

30. Yamasaki S: Intrahepatic cholangiocarcinoma: macroscopic type and stage classification. J Hepatobiliary Pancreat 10: 288-291, 2003.

31. Rattanasinganchan P, Leelawat K, Treepongkaruna SA Tocharoentanaphol C, Subwongcharoen S, Suthipongchai T and Tohtong R: Establishment and characterization of a cholangiocarcinoma cell line (RMCCA-1) from a Thai patient. World J Gastroenterol 12: 6500-6506, 2006

32. Livak KJ and Schmittgen TD: Analysis of relative gene expression data using real-time quantitative PCR and the 2[Delta Delta C(T)] method. Methods 25: 402-408, 2001.

33. Thuwajit C, Thuwajit P, Kaewkes S, Sripa B, Uchida K, Miwa M and Wongkham $\mathrm{S}$ : Increased cell proliferation of mouse fibroblast NIH-3T3 in vitro induced by excretory/secretory product(s) from Opisthorchis viverrini. Parasitology 129: 455-464, 2004.

34. Okamura N, Yoshida M, Shibuya A, Sugiura H, Okayasu I and Ohbu M: Cellular and stromal characteristics in the scirrhous hepatocellular carcinoma: comparison with hepatocellular carcinomas and intrahepatic chaolangiocarcinomas. Pathol Int 55: 724-731, 2005

35. Samoszuk M, Tan J and Chorn G: Clonogenic growth of breast cancer cells co-cultured in direct contact with serum-activated fibroblasts. Breast Cancer Res 7: R274-R283, 2005

36. Van Eyken P, Sciot R and Desmet VJ: Immunohistochemistry of cytokeratins in primary human liver tumors. APMIS (Suppl) 23: 77-85, 1991

37. Fischer HP, Altmannsberger M, Weber K and Osborn M: Keratin polypeptides in malignant epithelial liver tumors. Am J Pathol 127: 530-537, 1987.

38. Dulbecco R, Allen R, Okada S and Bowman M: Functional changes of intermediate filaments in fibroblastic cells revealed by a monoclonal antibody. Proc Natl Acad Sci USA 80: 1915-1918, 1983

39. Lebret SC, Newgreen DF, Thompson EW and Ackland ML: Induction of epithelial to mesenchymal transition in PMC42-LA human breast carcinoma cells by carcinoma-associated fibroblasts secreted factors. Breast Cancer Res 9: R19, 2007.
40. Ngan CY, Yamamoto H, Seshimo I, et al: Quantitative evaluation of vimentin expression in tumor stroma of colorectal cancer. $\mathrm{Br}$ J Cancer 96: 986-992, 2007.

41. San Francisco IF, DeWolf WC, Peehl DM and Olumi AF: Expression of transforming growth factor-beta 1 and growth in soft agar differentiate prostate carcinoma-associated fibroblasts from normal prostate fibroblasts. Int J Cancer 112: 213-218, 2004.

42. Ellis MJ, Singer C, Hornby A, Rasmussen A and Cullen KJ: Insulin-like growth factor mediated stromal-epithelial interactions in human breast cancer. Breast Cancer Res Treat 31: 249-261, 1994.

43. Frazier KS and Grotendorst GR: Expression of connective tissue growth factor mRNA in the fibrous stroma of mammary tumors. Int J Biochem Cell Biol 29: 153-161, 1997.

44. Nakamura T, Matsumoto K, Kiritoshi A and Tano Y: Induction of hepatocytye growth factor in fibroblasts by tumor-derived factors affects invasive growth of tumor cells: in vitro analysis of tumor-stromal interactions. Cancer Res 57: 3305-3301, 1997.

45. Ponten F, Ren Z, Nister M, Westermark B and Ponten J: Epithelial-stromal interactions in basal cell cancer: the PDGF system. J Investig Dermatol 102: 304-309, 1994.

46. Yan G, Fukabori Y, McBride G, Nikolaropolous S and McKeeham WL: Exon switching and activation of stromal and embryonic fibroblast growth factor (FGF)-FGF receptors genes in prostate epithelial cells accompany stromal independence and malignancy. Mol Cell Biol 13: 4513-4522, 1993.

47. Lohr M, Schmidt C, Ringel J, Kluth M, Muller P, Nizze H and Jesnowski R: Transforming growth factor- $\beta 1$ induces desmoplasia in an experimental model of human pancreatic carcinoma. Cancer Res 61: 550-555, 2001.

48. Akhurst RJ: TGF- $\beta$ antagonists: why suppress a tumor suppressor? J Clin Invest 9: 1533-1536, 2002.

49. Paweletz CP, Charboneau L, Bichesel VE, et al: Reverse phase protein microarrays which capture disease progression show activation of pro-survival pathways at the cancer invasion front Oncogene 20: 1981-1989, 2001.

50. Vogetseder W, Feichtinger H, Schulz TF, et al: Expression of 7F7-antigen, a human adhesion moleucle identical to intercellular adhesion molecule-1 (ICAM-1) in human carcinomas and their stromal fibroblasts. Int J Cancer 43: 768-773, 1989.

51. Orimo A, Tomioka Y, Shimizu Y, et al: Cancer-associated myofibroblasts possess various factors to promote endometrial tumor progression. Clin Cancer Res 7: 3097-3105, 2001.

52. Olumi AF, Dazin P and Tlsty TD: A novel coculture technique demonstrates that nomal human prostatic fibroblasts contribute to tumour formation of $\mathrm{LNCaP}$ cells by retarding cell growth. Cancer Res 58: 4524-4530, 1998

53. Liotta LA and Kohn EC: The microenvironment of the tumourhost interface. Nature 411: 375-379, 2001.

54. Friedman SL, Maher JJ and Bissell DM: Mechanisms and therapy of hepatic fibrosis: report of the AASLD single topic basic research conference. Hepatology 32: 1403-1408, 2000.

55. Bilimoria MM, Lauwers GY, Doherty DA, et al: Underlying liver disease, not tumour factors, predicts long-term survival after resection of hepatocellular carcinoma. Arch Surg 136: 528-535, 2001. 